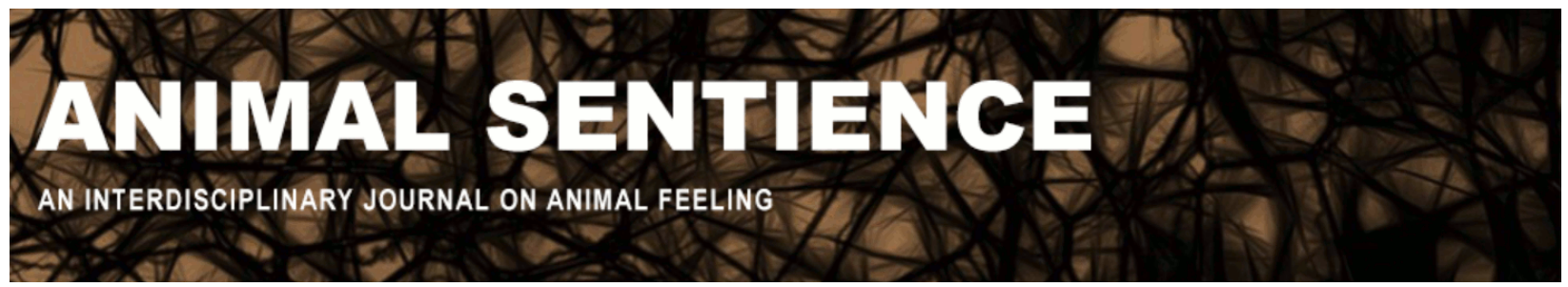

$\mathrm{Ng}$, Yew-Kwang (2017) Justifying the precautionary principle with expected netwelfare maximization. Animal Sentience 16(12)

DOI: $10.51291 / 2377-7478.1238$

Date of submission: 2017-10-29

Date of acceptance: 2017-11-03 (c) 


\title{
Justifying the precautionary principle with expected net-welfare maximization
}

Commentary on Birch on Precautionary Principle

\author{
Yew-Kwang $\mathrm{Ng}$ \\ Economics \\ Nanyang Technological University
}

\begin{abstract}
The precautionary principle may be best justified on the principle of expected netwelfare/benefit maximization; there is no conflict between the two principles. We should want to be more cautious for cases with high benefit-to-cost ratios; there should thus be different degrees of precaution. For measures to reduce extinction-threatening environmental disruption or to reduce animal suffering that cost us little or nothing, we should adopt them even for species having only a small likelihood of being sentient, i.e., we should be more cautious. This argument is based on welfarism, which I strongly defend elsewhere ( $\mathrm{Ng} 1990$ \& forthcoming).
\end{abstract}

\begin{abstract}
Yew-Kwang $\mathrm{Ng}$ is Winsemius professor in economics at Nanyang Technological University. He is a fellow of the Academy of Social Sciences in Australia and Distinguished Fellow of the Economic Society of Australia. He has published over two hundred refereed papers in economics, biology, cosmology, mathematics, philosophy, psychology, and sociology. His recent books include: Common Mistakes in Economics by the Public, Students, Economists and Nobel Laureates (open access). www.ntu.edu.sg/home/ykng/
\end{abstract}

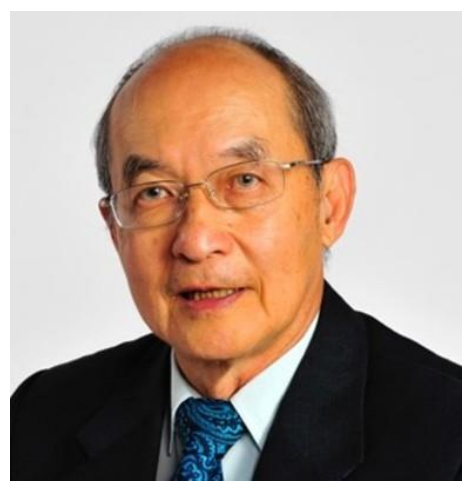

I largely support the precautionary principle for many issues including environmental protection and animal welfare. I also largely agree with the main arguments of Birch's (2017) target article. However, some points merit elaboration.

1. Precautionary principle justified upon expected net welfare/benefit maximization. The most important point in the target article that requires qualification is this. In my view, there is no conflict between the precautionary principle, properly used, and the expected netbenefit/welfare principle ('weighing expected costs against expected benefits'). Thus, I find the following statement misleading, if not almost opposite to the correct position: 'if one feels that it is never appropriate to act without weighing expected costs against expected benefits, then one will be led to reject the precautionary principle' (Birch 2017, p. 4).

Why do I mention the environment and animal welfare as the examples in which I support the precautionary principle? It is precisely because the expected harms here are very large. Most environmental scientists agree that if we continue with business as usual without stepping up our 
environmental protection measures including reducing greenhouse gases, it is highly likely that the living environment will be irreparably harmed; extinction of the whole human species and even the whole living world may ensue. Many believe that we have only a window of a few decades to start doing something to prevent this horrendous outcome. Yes, their estimates of likelihood (some believe in virtual certainty) may be too high; their estimates of the length of window of opportunity may be too narrow. However, since the potential harm of extinction is horrendous, we cannot accept even a probability of just $1 \%$ or even lower.

If you have bought an air ticket and a friend tells you that a report with only $10 \%$ reliability says that a time-bomb will be placed on that flight, would you change your flight? I would change if reliability were only of $0.1 \%$. If the $99.9 \%$ turned out to be the case, I would have lost some time and been inconvenienced. If I tried to avoid this inconvenience and the $0.1 \%$ turned out to be true, I would lose my life. This is more than a thousand times more important than the inconvenience. It is rational or expected net-welfare-maximizing (on the equivalence of these two, see Ng 1984) for me to change my flight. This is another instance of the correct application of the precautionary principle. However, a very small risk of say $0.00001 \%$ (about the risk of an average commercial flight of a reliable airline) has to be accepted for many purposes; otherwise, one should never fly. Thus, it all depends on the rough (precision is usually not possible) estimation of the relevant costs, benefits and probabilities. For the case of environmental protection, we should be even more cautious (and be willing to incur much more costs), as the stake is many times greater than one human life ( $\mathrm{Ng} \mathrm{2016a).}$

For the case of animal welfare protection, we know with virtual certainty that, for cases like factory chicken farming, enormous suffering has been inflicted on the poor animals that could be drastically reduced at little or no cost for humans ( $\mathrm{Ng} \mathrm{2016b).} \mathrm{For} \mathrm{fish} \mathrm{and} \mathrm{invertebrates,} \mathrm{we}$ are less certain that they can suffer. However, if they could, the unnecessary suffering imposed upon them could again be drastically reduced at little or no cost for humans. The precautionary principle thus calls for assuming that they could suffer, unless it is shown with virtual certainty that they could not.

Putting the point more precisely, for both environmental protection and animal welfare, we may be reasonably confident that the relevant probability (extinction/suffering) falls between say $0.00001 \%$ and $90 \%$. (The precise range does not affect the validity of the point much.) For measures such as taxing serious pollution or greenhouse gas emission or legislating for minimum cage sizes for chicken farming - which do not cost us much in comparison to the amount of enormous suffering/damages prevented - we need the relevant probability to fall well below about $0.01 \%$ to justify non-action. This is possible, as there is a small but non-negligible probability between the range of $0.01 \%$ and $0.00001 \%$ (called A). However, for any reasonable probability or likelihood distribution between $0.00001 \%$ and $90 \%$, there is a much larger probability between $0.01 \%$ and $90 \%$ (B). If we undertook the precautionary costs to avoid catastrophes and A proved to be the case, we might have incurred some significant but not enormous costs unnecessarily. However, if we did not undertake the precautionary measures and the more likely B proved to be the case, the outcome would have been disastrous. Thus, whether we use expected netwelfare/benefit maximization or the precautionary principle, we should proceed to tax large emissions of greenhouse gases and legislate cage sizes until the less than $0.01 \%$ probability is established beyond reasonable doubt. In other words, the precautionary principle is most reasonably justified, in my view, on the basis of the maximization of expected net welfare/benefit. 
Perhaps the precautionary principle is putting the point in vaguer terms while welfaremaximization is putting the point more precisely, but they are certainly not in conflict.

On the other hand, I do not support or use the precautionary principle in decisions like whether I should buy clothes on sale but without the option of wearing them to check whether the size fits. If the discount is big enough, I will just guess the appropriate size and take a chance. If it turns out not to fit, my loss is not horrendous. There is no need to use the precautionary principle. Thus, when or whether it is appropriate to use the precautionary principle depends precisely on "weighing expected costs against expected benefits," though usually on some imprecise terms. Not only is there no conflict between the two principles, the precautionary principle may in fact be best justified on the basis of the principle of expected net-welfare/benefit maximization.

It is true that the latter principle is based on welfarism (in its usual sense in economics and philosophy, namely, that what is of intrinsic value is the welfare of sentients; this is somewhat different from what radical animal advocates mean by welfarism). I have strongly defended welfarism elsewhere ( $\mathrm{Ng} \mathrm{1990;}$; and updated, in expanded version in $\mathrm{Ng}$, forthcoming, Appendix B). I may go along with animal liberation in some way. However, the justification for liberation is for the reduction of their suffering and/or the promotion of their welfare; few, if any, want liberation for liberation's sake. Quite likely, even without any exploitation and encroachment from humans, if animals will still be largely suffering negative welfare (as argued in Ng 1995), liberating them and leaving them alone will not be enough. We should hope to help reduce their suffering at least in the future with our own economic, scientific, and ethical advancements. Thus, scientific research is very important, even at some cost to the sentient animals now, if not imposed unnecessarily and excessively. Again, "weighing expected costs against expected benefits."

As a consequence of my purely welfarist stance, I find Birch's point about the distinction between sentient and non-sentient living things perfectly sensible. However, a commentator strongly disagrees with Birch:

"For me a smoking gun sentence in Birch's paper is this one: 'If an animal is not regarded as sentient, practices that would be considered clearly inhumane if performed on a vertebrate, such as the removal of limbs without anesthetic or analgesic, may be allowed to persist.' As I read this sentence, it implies that removing the limbs [or even killing] of an animal ... could be humane, provided it is done 'painlessly. '"' (Marks 2017)

First, this is conflating killing a non-sentient living thing and killing a sentient one painlessly. I do not want to be killed painlessly as I expect to live a life of positive net welfare and to continue to contribute to the welfare of other sentients. However, if I were a non-sentient living thing, I would not mind (even if I could) being killed if my death does not cause any harm to sentients. Life itself is not of value. Net welfare is. If we have ten to the power of a million living things each suffering big negative welfare but living perpetually, that is a dismal world worse than having all of them killed instantly and painlessly. It is suffering and welfare (三 happiness) that are of concern/value, not killing and life as such, though killing, especially of sentients, is usually welfare-reducing. 
2. Different degrees of precaution. After clarifying the basic point above, I find the main arguments of the target article reasonable, including the choice of 'order' as a reasonable compromise between 'species or genus' and 'class.' Two more points of clarification or supplementation can be added:

First, on the specific practical proposals of BAR and ACT, they should be accepted as sufficient conditions for action, not as necessary conditions, at least for those actions involving relatively little cost in comparison to their benefits, such as taxing serious pollution and regulating cage size as discussed above. This is because Birch's "statistically significant evidence, obtained by experiments that meet normal scientific standards, of the presence of at least one credible indicator of sentience in at least one species of that order" may already be quite demanding for some cases. Before that evidence is established, it may still be prudent to take precautionary actions for cases with high benefit-to-cost ratios.

In other words, we should have different degrees of precaution, depending on the expected benefit-to-cost ratios; the higher the ratio, the higher the justified degree of precaution. My position here is not surprising, as I accept the precautionary principle as a way to maximize expected net welfare/benefit in the absence of information allowing for more precision. This may not be that different from the position of Birch: "when there is a live scientific hypothesis that posits a causal relationship between human action and a seriously bad outcome, we should set an intentionally low evidential bar for the acceptance of that hypothesis in the context of formulating policy" (p. 3). Going just a little step further, we should naturally arrive at: the height of the evidential bar should depend on how bad the outcome would be (relative to the cost of prevention).

Second, there may be a way to lessen the difficulty of establishing an affective sentience with respect to many species of animals: If we accept that affectively sentient species must be plastic in their behavior, as shown to follow from some compelling axioms in $\mathrm{Ng}$ (1995), we can focus on species that are plastic, ruling out species for which we have high confidence that their behavior is not plastic. Other traits, such as motility, may be much less relevant, if not completely irrelevant.

\section{References}

Birch, J. (2017). Animal sentience and the precautionary principle. Animal Sentience 16(1). Marks, J. (2017). Changing the subject. Animal Sentience 16(5).

$\mathrm{Ng}$, Y-K. (1984). Expected subjective utility: Is the Neumann-Morgenstern utility the same as the Neoclassical's? Social Choice and Welfare, 1: 177-186.

$\mathrm{Ng}$, Y-K. (1990). Welfarism and utilitarianism: A rehabilitation. Utilitas, 2(2): 171-193.

$\mathrm{Ng}, \mathrm{Y}$-K. (1995). Towards welfare biology: Evolutionary economics of animal consciousness and suffering. Biology \& Philosophy, 10(3), 255-285. http://dx.doi.org/10.1007/bf00852469

$\mathrm{Ng}$, Y-K. (2016a). The importance of global extinction in climate change policy, Global Policy, 7(3): 315-322. doi: 10.1111/1758-5899.12318.

$\mathrm{Ng}, \mathrm{Y}-\mathrm{K}$. (2016b). How welfare biology and commonsense may help to reduce animal suffering. Animal Sentience 7(1).

$\mathrm{Ng}$, Y-K. (forthcoming). Markets and Morals: Justifying Kidney Sale and Legalizing Prostitution, contract with Cambridge University Press. 


\section{ANIMAL CONSCIOUSNESS}

On November 17-18, 2017, the NYU Center for Mind, Brain and Consciousness, the NYU Center for Bioethics, and NYU Animal Studies will host a conference on Animal Consciousness.

This conference will bring together philosophers and scientists to discuss questions such as: Are invertebrates conscious? Do fish feel pain? Are nonhuman mammals self-conscious? How did consciousness evolve? How does research on animal consciousness affect the ethical treatment of animals? What is the impact of issues about animal consciousness on theories of consciousness and vice versa? What are the best methods for assessing consciousness in nonhuman animals?

\section{Speakers and panelists include:}

Colin Allen (University of Pittsburgh, Department of History \& Philosophy of Science), Andrew Barron (Macquarie, Cognitive Neuroethology), Victoria Braithwaite (Penn State, Biology), Peter Carruthers (Maryland, Philosophy), Marian Dawkins (Oxford, Zoology), Dan Dennett (Tufts, Philosophy), David Edelman (San Diego, Neuroscience),

Todd Feinberg (Mt. Sinai, Neurology), Peter Godfey-Smith (Sydney, Philosophy), Lori Gruen (Wesleyan, Philosophy), Brian Hare (Duke, Evolutionary Anthropology), Stevan Harnad (Montreal, Cognitive Science), Eva Jablonka (Tel Aviv, Cohn Institute), Björn Merker (Neuroscience), Diana Reiss (Hunter,

Psychology), Peter Singer (Princeton, Philosophy), Michael Tye (Texas, Philosophy)

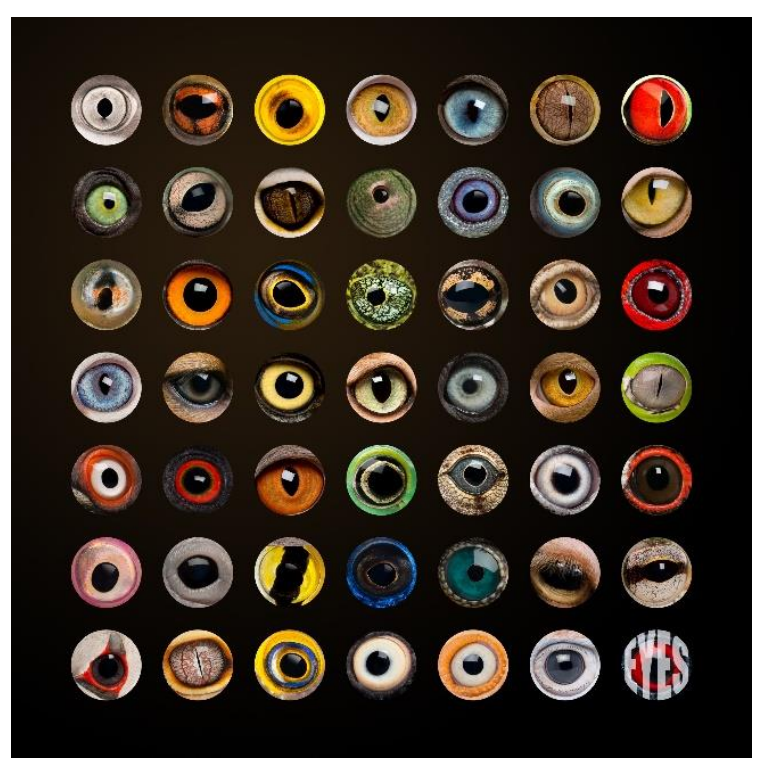

Organizers: Ned Block, David Chalmers, Dale Jamieson, S. Matthew Liao.

The conference will run from 9am on Friday November 17 to $6 \mathrm{pm}$ on Saturday November 18 at the NYU Cantor Film Center (36 E 8th St).

Friday sessions will include "Invertebrates and the evolution of consciousness", "Do fish feel pain?", and "Animal consciousness and ethics".

Saturday sessions will include "Animal self-consciousness", "Animal consciousness and theories of consciousness", and a panel discussion.

A detailed schedule will be circulated closer to the conference date.

Registration is free but required.

\section{Register here.}

\section{See also the conference website}

